\title{
An epidemiological study of pleuropulmonary paragonimiasis among pupils in the peri-urban zone of Kumba town, Meme Division, Cameroon

\author{
Roger Moyou-Somo*1,2, Charles Kefie-Arrey², Georges Dreyfuss ${ }^{3}$ and \\ Michel Dumas ${ }^{3}$
}

\begin{abstract}
Address: ${ }^{1}$ Medical Research Center, Institute of Medical Research and study of Medicinal Plants (IMPM), Yaounde, Cameroon, ${ }^{2}$ Department of Parasitology and Infectious Diseases, Faculty of Medicine and Biomedical Sciences, University of Yaounde I, Yaounde, Cameroon and ${ }^{3}$ Institut de Neurologie Tropicale, Limoges, France
\end{abstract}

Email: Roger Moyou-Somo* - roger_moyou@yahoo.fr; Charles Kefie-Arrey - kefiecharle@yahoo.fr; Georges Dreyfuss - g.dreyfuss@pharma.unilim.fr; Michel Dumas - ient@unilim.fr

* Corresponding author

Published: 16 December 2003

BMC Public Health 2003, 3:40
Received: 01 October 2003

Accepted: 16 December 2003

This article is available from: http://www.biomedcentral.com/I47I-2458/3/40

(c) 2003 Moyou-Somo et al; licensee BioMed Central Ltd. This is an Open Access article: verbatim copying and redistribution of this article are permitted in all media for any purpose, provided this notice is preserved along with the article's original URL.

\begin{abstract}
Background: Paragonimiasis have previously been reported in two zones of the Southwest Province of Cameroon including the Kupe mountain and Mundani foci. The aim of this study was to investigate the presence and epidemiology of paragonimiasis in the peri-urban zone of Kumba, Meme Division, located about 50 km away from the Kupe mountain focus.
\end{abstract}

Methods: Pupils of several government primary schools in 5 villages around Kumba underwent both parasitologic and clinical investigations in search of signs and symptoms of paragonimiasis. Mycobacterium tuberculosis was also searched for in the differential diagnosis.Freshwater crabs from neighbouring streams in the five villages were dissected in search of paragonimus metacercariae.

Results: Out of a total of I482 pupils examined in all five villages, 309 individuals (I47 males and I62 females) were recruited for this study based on the presence of one or more signs or symptoms of paragonimiasis. Eggs of Paragonimus africanus were found in stools and/or sputum of pupils from all five villages, giving an overall paragonimus prevalence of 2.56\%. There was no significant difference in the disease prevalence between the villages $\left(X^{2}=8.36, P=0.08\right)$. The prevalence of Paragonimus africanus eggs amongst pupils with symptoms of paragonimiasis was $12.3 \%$ (38 of 309 ). Males were infected more than females (I7.0\% versus $8.0 \%)$, but the difference was not significant $\left(X^{2}=5.76, P=0.16\right)$. All the 38 paragonimus egg positive subjects presented with cough, $23(60.53 \%)$ complained of chest pain while $16(42.1$ I $\%)$ had haemoptysis. Stool examinations also detected some intestinal parasites including Ascaris lumbricoides (29.45\%), Trichuris trichiura (6.47\%), Necator americanus (2.27\%), Strongyloides stercoralis (1.62\%), Enterobius vermicularis (0.65\%), and Entamoeba histolytica (4.53\%). No case of M. tuberculosis was noted. Out of a total of 85 dissected crabs (Sudanonautes africanus), $6.02 \%$ were infected with paragonimus metacercariae.

Conclusion: In addition to the two previously described paragonimiasis foci of Kupe mountain and Mundani, the identification of autochthonous cases of paragonimiasis in the peri-urban zone of Kumba town, makes the South West Province the most endemic zone of paragonimiasis in Cameroon at present. 


\section{Background}

Paragonimiasis is a food-borne disease caused by lung flukes of the genus Paragonimus. The disease is common in Southeast Asia, South America, and Africa, with an associated 21 million people infected the world over [1]. Human infection is acquired by the consumption of raw or partially cooked crustaceans including crayfishes and crabs. The acute phase of the infection (parasite invasion and migration) is clinically indicated by diarrhoea, abdominal pain, fever, cough, urticaria, hepatosplenomegaly, and eosinophilia. The chronic phase (pulmonary infection) is characterised by cough, haemoptysis, chest pain and radiographic abnormalities that can persist even several years after adequate treatment[2]. Extra pulmonary location of the adult worms especially in the brain results in more severe manifestations. Two species, Paragonimus africanus and Paragonimus uterobilateralis are known as the main pathogens of human paragonimiasis in Africa. In Cameroon, only P africanus was found associated with human paragonimiasis. $P$ uterobilateralis has so far been reported only in the animal model. Five well known foci of paragonimiasis exist in Cameroon, including the mount Kupe [3-6] and the Mundani [7] in the South West Province, the Mbam and the Nyong [4] in the Centre Province, and the Ntem [4] in the South Province. The present study was undertaken to explore the epidemiology of pleuropulmonary paragonimiasis in the periurban zone of Kumba town, located $50 \mathrm{Km}$ from the Kupe mountain focus, following a report of cases received at the Kumba district hospital.

\section{Methods \\ Study site}

Kumba area is in the rain forest zone of South - West Province of Cameroon, approximately $100 \mathrm{Km}$ from the Atlantic Ocean $\left(4^{\circ} 3^{\prime} \mathrm{N}, 9^{\circ} 3^{\prime} \mathrm{W}\right)$. It is in a plain which is surrounded by three volcanic mountains: the Rumpy hills (1765 m) to the north - west, the Kupe mountain (2050 $\mathrm{m})$ to the north - east, and the Cameroon mountain ( $4094 \mathrm{~m})$ to the south - west. The annual average temperature is $24^{\circ} \mathrm{C}$ and the relative humidity varies from 52 to $74 \%$.

The study population was made-up of pupils from government primary schools in some five villages around Kumba town including Barombi-Kang, Ediki, Mabonji, Etam and Teke (figure 1). The main economic activity of the study population is agriculture (food and cash crop farming and plantation agriculture by the Cameroon Development Corporation). Included in the study, was any pupil who had cough associated or not to another paragonimiasis sign or symptoms, and who has been living in the area for at least one year.

\section{Clinical and parasitologic investigations}

The study was conducted from March to July 2001 with pupils examined at their various campuses. Given the apprehension about written consents in the rural communities of Cameroon, oral informed consent was obtained from subjects aged 15 years and above, or from the parents or legal guardians of children aged below 15 years, witnessed by the headmasters and the village chiefs. The study was reviewed and approved by the Cameroon National Ethics Committee. Each participant provided a brief medical history and underwent a clinical examination for signs and symptoms of paragonimiasis (cough, haemoptysis and chest pain). Thereafter, they were given 2 small snap-cap plastic containers, 2 thin applicator sticks, and some toilet paper. They were instructed to transfer a small quantity of sputum into one container and a small quantity of stool into the other one, and return them to the research team. Each specimen was then mixed with a small quantity of sodium azide and transported to the base laboratory in Yaounde for analysis. To each sputum sample was added twice its volume of $4 \%$ caustic soda followed by adequate mixing and centrifugation at $1500 \mathrm{rpm}$ for 5 minutes. The resulting pellet was transferred unto a microscope slide and observed under a light microscope at $10 \mathrm{X}$ and $40 \mathrm{X}$ magnification for the presence of paragonimus eggs. It should be noted that, though the Eggs of both species are morphologically identical, those of $P$ africanus are significantly smaller. Each specimen was also stained with Ziehl Nielsen and examined at 100X magnification for the presence of Mycobacterium tuberculosis The stool samples were treated and analysed using a standard Rithie concentration technique to detect paragonimus eggs and the presence of other coinfecting parasites. All the paragonimiasis patients were treated with praziquantel at a dose of $3 \times 25 \mathrm{mg} / \mathrm{Kg}$ of body weigh per day for 3 consecutive days [6].

\section{Collection and dissection of crabs}

With the assistance of the pupils, crabs were collected from the neighbouring streams in each of the villages using fishing baskets tufted with palm nuts and cassava. The baskets were placed at various points in the streams overnight and only checked the next day for the presence of crabs. Some crabs were equally dug out of small borrows along the stream beds or picked under some stones in the streams. The collected crabs were transported in perforated plastic buckets each with a lid to the laboratory where they were fed with palm nuts and slices of cassava until dissected. The hard shell of each crustacean was removed using a small metal hammer and the muscle tissues beneath extracted using a small metallic spatula, into a petri dish. The obtained sample was then examined under a dissecting microscope at a magnification of $10 \mathrm{X}$ and $25 \mathrm{X}$. 


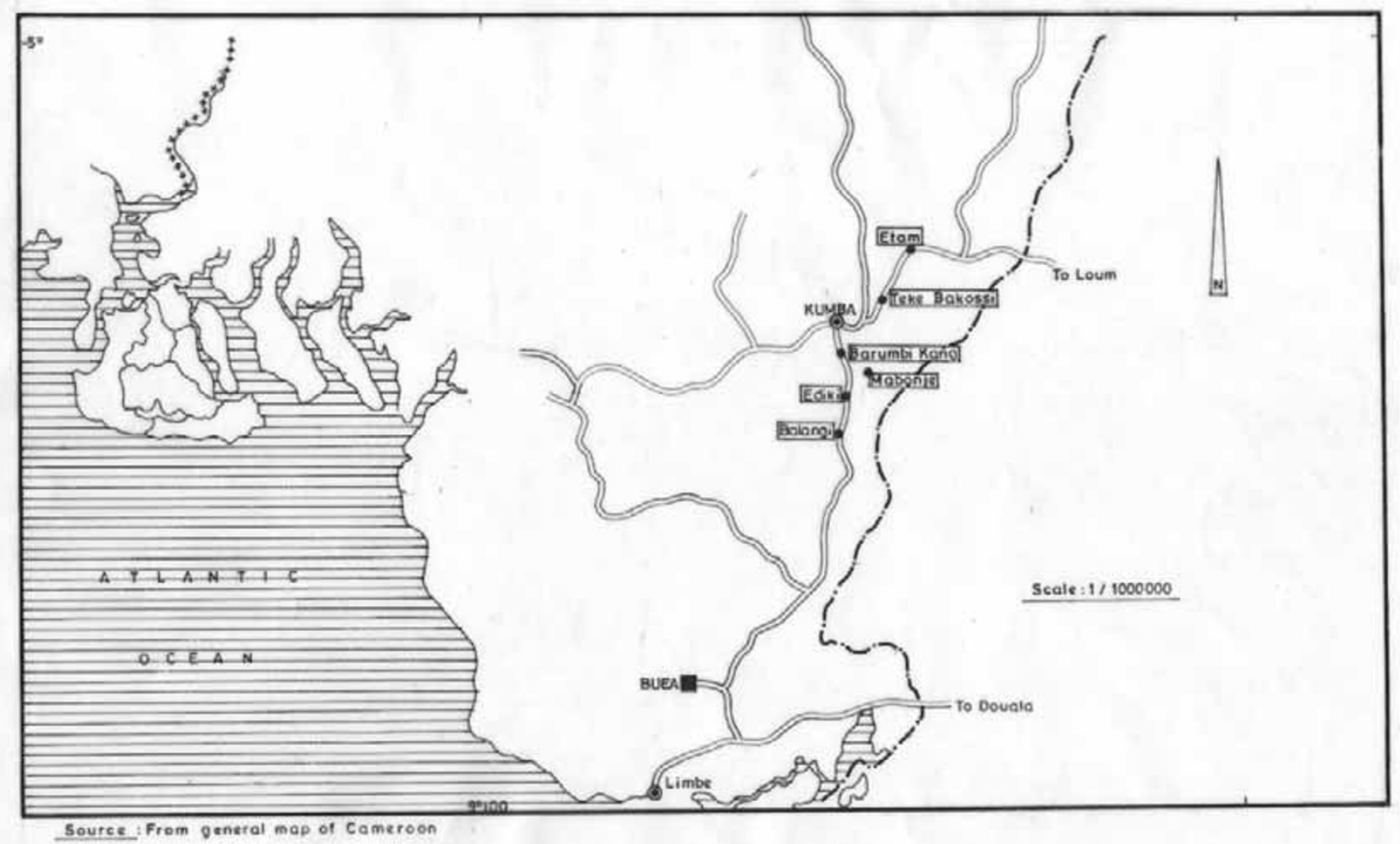

Figure I

Map of the study zone

\section{Statistical analysis}

Statistical analysis was performed with Epi-Info sofware, 5.0 version. Comparison of groups with normally distributed data was made by analysis of variance after application of Bartlett's test for homogeneity of variance and proportion by the Fisher exact test and the chi-square test. P-value $<0.05$ were considered statistically significant.

\section{Results}

\section{Parasitologic and clinical findings}

A total of 1482 pupils were examined in all the five village schools. Of this pupils, three hundred and nine individuals (147 males and 162 females) presented with one or more signs of paragonimiasis, and thus were recruited for this study and distributed as follows: 61 from BarombiKang village, 60 from Ediki, 66 from Etam, 61 from Mabonji and 61 from Teke. They ranged in age from 4 to 17 years $($ mean $=9.79 \pm 2.83$ years in males and $9.04 \pm$ 2.47 years in females).

Paragonimus africanus eggs were detected in the stool and/ or sputum from pupils of all the five schools giving an overall paragonimiasis prevalence of $2.56 \%$ in school children of the five villages. The prevalence of $P$. africanus eggs in stool and/or sputum specimens among symptomatic pupils was $12.3 \%$ (38 of 309). The results showed a greater proportion (17\%) of the symptomatic males population to be more infected than the females $(8 \%)$, but this sex difference was not significant $\left(\mathrm{X}^{2}=5.76, \mathrm{P}=0.16\right)$. However, the prevalence was significanly high in males than in females in the age group $6-10$ years $\left(\mathrm{X}^{2}=4.76, \mathrm{P}\right.$ $=0.03$ ) (table 1$)$. The highest prevalence was recorded in Teke, followed by Etam, while Mabonji had the least prevalence rate. No significant difference was however noted in the prevalence between the five villages $\left(\mathrm{X}^{2}=8.36, \mathrm{P}=\right.$ 0.08) (table 2).

Of the 38 paragonimus egg - positive cases, all presented with cough $(100 \%), 23(60.53 \%)$ complained of chest pain and $16(42.11 \%)$ had haemoptysis. No patient presented with fever or altered general status. Stool examinations also detected some intestinal parasites including Ascaris lumbricoides (29.45\%), Trichuris trichiura (6.47\%), Necator americanus $(2.27 \%)$, Strongyloides stercoralis 
Table I: Distribution of egg-positive cases among symptomatic patients by ages and sex

\begin{tabular}{|c|c|c|c|c|c|c|}
\hline \multirow[b]{2}{*}{ Age (years) } & \multicolumn{2}{|c|}{ Male } & \multicolumn{2}{|c|}{ Female } & \multicolumn{2}{|c|}{ Total } \\
\hline & number examined & $\begin{array}{c}\text { number positive } \\
\text { (\%) }\end{array}$ & number examined & $\begin{array}{c}\text { number positive } \\
(\%)\end{array}$ & number examined & $\begin{array}{c}\text { number positive } \\
\text { (\%) }\end{array}$ \\
\hline$<5$ & 12 & $4(33.3)$ & 13 & I (7.7) & 25 & $5(20)$ \\
\hline $6-10$ & 70 & $12(17.1)$ & 105 & $7(6.7)$ & 175 & $19(10.9)$ \\
\hline $11-15$ & 63 & $9(14.5)$ & 44 & 5 (II.4) & 107 & $14(13.1)$ \\
\hline$>15$ & 2 & $0(0.0)$ & 0 & $0(0.0)$ & 2 & $0(0.0)$ \\
\hline Total & 147 & $25(17.0)$ & 162 & $13(8.0)$ & 309 & $38(12.3)$ \\
\hline
\end{tabular}

Table 2: Global prevalence of human paragonimiasis in relation to school

\begin{tabular}{cccc}
\hline Schools & Total pupil population & number of eggs-positive cases & Prevalence (\%) \\
\hline GS Barombi-Kang & 379 & 9 & 2.37 \\
GS Ediki & 298 & 6 & 2.01 \\
GS Etam & 231 & 7 & 3.03 \\
GS Mabonji & 218 & 1 & 0.46 \\
GS Teke & 356 & 15 & 4.21 \\
TOTAL & 1482 & 38 & 2.56 \\
\hline
\end{tabular}

GS = Government School

(1.62\%), Enterobius vermicularis (0.65\%), and Entamoeba histolytic a $(4.53 \%)$. No case of Mycobacterium tuberculosis was detected.

\section{Prevalence of P. africanus metacercariae in crabs}

A total of 85 freshwater crabs, Sudanonautes africanus were caught from streams within the study villages, and dissected. Table 3 gives the distribution of the metacercariaepositive cases following the dissection of crabs. The overall crab infestation rate was calculated to be $6.02 \%$, with the highest rate $(18.75 \%)$ recorded in Teke village where the prevalence of human infestation was also highest. No infected crab was identified in Ediki and Mabonji villages. However, the pattern of crab infestation in the five villages did not show any significant difference $\left(\mathrm{X}^{2}=2.11, \mathrm{P}=\right.$ $0,35)$.

All the children who were examined had at least once consumed crabs and $68.42 \%$ of them declared that they prepared their crustaceans by roasting, $18.42 \%$ by boiling and $13.16 \%$ by frying in oil. These children related the change in colour of the crab shell during preparation to its readiness for consumption, the duration of cooking not withstanding

\section{Discussion}

Previous studies indicated the presence of paragonimiasis in two zones of the Southwest Province of Cameroon including the Kupe mountain focus in the Lower Bakossi area, Kupe Manengumba Division [3-6] and the Mundani focus [7] in Lebialem Division. This study was aimed at investigating the presence and epidemiology of paragonimiasis in the peri-urban zone of Kumba, Meme Division, located about $50 \mathrm{~km}$ away from the Kupe mountain focus. A total of 1482 school pupils in five village schools in the periphery of Kumba town were examined for the presence of paragonimus eggs in their stools and/or sputum. The results show an overall prevalence of $2.56 \%$ for paragonimiasis in the five neighbouring villages. This value is certainly an underestimate of the actual situation in the study zone, given the stringency of the standard diagnostic method used to identify typical operculated ova in stool and sputum. In a similar study carried out at the Kyusyu Island, Japan, Mukae and others [8] detected paragonimus eggs in the sputum and/or stools of only $31 \%$ of patients, the other cases being detected either by immunodiagnosis or bronchoscopic examination which appear more sensitive than the standard methods. Such sensitive tools were unfortunately not employed in this study due to their costs. The main differential diagnosis of paragonimiasis is pleuropulmonary tuberculosis. We had no case of Mycobacterium tuberculosis infection. This observation is rather surprising giving the recent increase in the prevalence of tuberculosis following the spread of HIV infection in Tropical Africa. However, it should be noted that the age of our study population, made-up of primary 
Table 3: Distribution of Metacercariae-positive cases according to village

\begin{tabular}{|c|c|c|c|}
\hline Villages & number of crabs dissected & $\begin{array}{c}\text { number of metacer-cariae-positive } \\
\text { cases }(\%)\end{array}$ & Total number of metacercariae \\
\hline Barombi-Kang & 18 & I (5.65) & 20 \\
\hline Ediki & 15 & $0(0.00)$ & 0 \\
\hline Etam & 17 & I (5.88) & 62 \\
\hline Mabonji & 19 & $0(0.00)$ & 0 \\
\hline Teke & 16 & $3(18.75)$ & 126 \\
\hline Total & 85 & $5(6.02)$ & 208 \\
\hline
\end{tabular}

school children, is below that of the population at risk of HIV infection. In any case, clinicians should consider paragonimiasis in the differential diagnosis of tuberculosis, especially in cases of resistance to anti-tuberculosis treatment.

In the Kupe mountain focus, a significantly higher prevalence was noted in females compared to the males group. This sex difference was attributed to the believe by the Bakossi tribe which constitutes the population of the zone that crabs are a valuable aid to fertility in females $[3,5,6]$. On the contrary, in the present study, males are more infected than females (17.0\% versus $8.0 \%$ ) even though the difference was not significant. In fact the population of the present study is rather cosmopolitan and the pattern of infection should be different.

Geographical difference in prevalence could not be traced to the rate of infestation of crabs. Most of the streams in this area, have a common watershed, the Rumpi Hills and crabs can migrate from one stream to the other. Also, children from neighbouring villages can harvest crabs from the same streams.

All the children who were examined declared that they consumed crabs and that during the cooking of their crustaceans, they associated the change of colour of the shell of the crab with its readiness for consumption, the duration of cooking not withstanding. Thus, it could be said that these children consumed inadequately cooked crabs. These observations appear to support the results of others $[1,9]$. The present study also shows that common symptoms are similar to those reported elsewhere [10-12].

In conclusion, this study has enabled the identification of autochthonous cases of paragonimiasis in the peri-urban zone of Kumba, Meme Division, Cameroon. It is however uncertain in this study wether this zone is independent or belongs to the Kupe mountain focus, thus calls for further investigations. In any case, the South West Province appears to be the most endemic zone of paragonimiasis in Cameroon at present.

\section{Acknowledgements}

We are grateful to the personnel of the Kumba Tropical Research Station, the headmasters, and the school children of the visited villages for their cooperation. This study partially received financial support from the Cameroon Institute of Medical Research and Study of Medicinal Plants (IMPM) and from the Institute of Tropical Neurology, Limoges France.

\section{References}

I. World Health Organisation (WHO): Control of food - borne trematode infections. Report of WHO study group. Technical Report Series N849. Geneva 1995

2. Moyou-Somo R, Tagni-Zukam D: Paragonimiasis in Cameroon: Clinico radiological features and treatment outcome. Med Trop (Mars) 2003, 63:163-167.

3. Zahra A: Paragonimiasis in the Southern Cameroons: a preliminary report. West Afr Med J 1952, 25:75-82.

4. Ripert C, Carrie J, Ambroise Thomas P, Baecher R, Kum NP, Same Ekobo $A$ : Etude épidémiologique et clinique de la paragonimose au Cameroun, résultats du traitement par le Niclofolan. Bull Soc Path Exot I 981, 74:319-331.

5. Kum NP, Nchinda TC: Pulmonary paragonimiasis in Cameroon. Trans Roy Soc Trop Med Hyg 1982, 76:768-772.

6. Moyou-Somo R, Enyong P, Kouamouo J, Dinga JS, Couprie B, Ripert $C$ : Etude de la paragonimose dans 5 villages du département de la Mémé (Sud-ouest Cameroun). Résultats du traitement par le praziquantel. Rev Sc Tech Yaoundé 1983, 6-7:125-331.

7. Sam Abbenyi A: Paragonimose pulmonaire endemique au low mundani, (Arrondissement de Fontem au Sud-Ouest Cameroun). Bull Soc Path Exot 1985, 78(3):334-34I.

8. Mukae $\mathrm{H}$, Taniguchi H, Matsumoto N, Liboshi H, Ashitani J, Matsukura S, Nawa Y: Clinicoradiologic features of pleuropulmonary paragonimus westermani on Kyusyu Island, Japan. Chest 200I, I 20(2):5|4-20.

9. Barrett C: Parasitic pulmonary diseases: concise clinical studies. Am Rev Resp Dis 1982, I 26:558-563.

10. Razaque MA, Mutum SS, Singh TS: Recurrent haemoptysis? Think of paragonimiasis. Trop Doct 1991, 21:153-155.

II. De-Gentile L, Chabasse D: Pulmonary mycoses and parastosis. Ann Biol Clin (Paris) 1990, 4(I): I-8.

12. Bercovitz Z: Clinical studies on human lung fluke disease (endemic hemoptysis) caused by Paragonimus westermani infestation. Am J Trop Med 1937, 17:101-121.

\section{Pre-publication history}

The pre-publication history for this paper can be accessed here:

http://www.biomedcentral.com/1471-2458/3/40/prepub 